\title{
Understanding Effect of Operating Parameters on Thermal Performance of Closed Loop Pulsating Heat Pipe: An Experimental Study
}

\author{
D. A. Chavan* and V. M. Kale \\ Department of Mechanical Engineering. Indira College of Engineering and Management, Savitribai Phule Pune University, Pune India \\ Accepted 15 June 2016, Available online 20 June 2016, Special Issue-5 (June 2016)
}

\begin{abstract}
Enhancing performance of electronic components is causing in higher heat flux dissipation. Two phase passive devices are recognized solution for contemporary electronics thermal management. Closed loop Pulsating Heat Pipes (CLPHPS) have emerged as alternative to conventional heat transfer technologies. The aim of research work presented in this paper is to better understanding working mechanics and effect of operating parameters on performance of CLPHPs through experimental investigation. Experiments were conducted on a CLPHP made up of copper capillary tube of $1.78 \mathrm{~mm} I D \& 3 \mathrm{~mm} O D$, the lengths of the evaporator, adiabatic and condenser sections are $100 \mathrm{~mm}, 100 \mathrm{~mm}$ and $150 \mathrm{~mm}$ respectively. Afterwards effects of various parameters, including working fluids (Ethanol, Methanol and DI Water), the volumetric filling ratios (40\%, 50\%, 60\% and 70\%) and orientation (Vertical, Inclined at 450 with horizontal and horizontal) on thermal performance of the CLPHP investigate experimentally. The results shows that each fluids has its own optimum filling ratios for given geometry and performance is highly affected by variation of volumetric filling ratios. The results strongly demonstrate the effect of working fluids and volumetric filling ratios on the thermal performance of device. Significant insight into the operational regimes of the CLPHP has been gained.
\end{abstract}

Keywords: Closed Loop Pulsating Heat Pipe, Working Fluids, Volumetric filling ratio, Latent heat, Thermal resistance,

\section{Introduction}

After their invention in the nineties pulsating heat pipes (PHPs) have emerged as most promising device for heat transfer application especially suitable for thermal management of electronic components. Pulsating heat pipes are a new type of heat exchanger that can be useful in the context of the thermal management of electronic components (Khandekar, M. Groll, P. Charoensawan, S. Rittidech, \& P. Terdto, 2004) (Reay \& P.A. Kew, 2006) (Ma, 2015).

Pulsating heat pipes are different from conventional heat pipes in design and working principle. They are made from a long continuous capillary tube bent into many turns, with the evaporator and condenser sections located at these turns. Moreover, an optional adiabatic section may be placed between the evaporator and the condenser. There is no wick structure used in PHPs, so their simple and cheap structure has made PHPs very attractive compared with conventional heat pipes. The diameter of a PHP should be small enough so that vapor plugs can be formed by capillary action. Since the surface tension force is dominant over the gravitation force, the

*Corresponding author: D. A. Chavan working fluid will be put in slug-plug order in the PHP, these slugs and plugs are randomly distributed in the PHP after it is partially filled with working fluid (Zohuri, 2011). The input heat flux, which is the driving force, increases the pressure of vapor plugs in the evaporator, and the heat output decreases the pressure of vapor plugs in the condenser. This pressure difference between the evaporator and condenser results in the oscillation of vapor plugs and liquid slugs in the PHP. Therefore, heat is transported from the evaporator to the condenser region by means of local axial movements of the working fluid (sensible heat) and phase changes (latent heat). Due to the continuous heating of bubbles formed by nucleate boiling, there will not be steady-state vapor pressure equilibrium for an operating PHP. Therefore, this type of heat pipe is essentially a non-equilibrium heat transfer device $(\mathrm{H}$ B. Ma, 2008) (Kambiz Jahani, 2013) (Reay \& P.A. Kew 2006).

There are many parameters that affect performance of closed loop pulsating heat pipe (CLPHP). These can be summarized as the tube diameter, input heat flux, filling ratio, number of turns, inclination angle, and thermophysical properties of the working fluid. Many researchers have investigated these parameters 
experimentally and analytically (Groll, 2003). Among these researchers, Khandekar and co-workers have done the most comprehensive research on the thermal performance of PHPs. Khandekar et al. experimentally investigated the effects of different working fluids (water, ethanol, R-123), input heat flux, and filling ratio (range of $0 \%-100 \%$ ) on the thermal performance of a CLPHP. Their experimental setup was formed from a copper tube (ID $2.0 \mathrm{~mm}$, OD $3.0 \mathrm{~mm}$ ) with five turns in the evaporator section. In their experimental studies, valuable information related to the fundamental characteristics and operational regimes of CLPHPs was obtained. They concluded that for the given input heat flux range, a better performing and self-sustained thermally driven pulsating action of the device is only observed in the filling ratio range of $25-65 \%$, depending on the working fluid. Above this range of filling ratio, due to the lack of vapor plugs, the overall degree of freedom and the pumping action of bubbles are deficient for generating pulsations inside the tubes. Therefore, the thermal performance of CLPHPs would not be suitable, below a certain range of filling ratio, the probability of partial dry-out of the evaporator and reaching the critical state exists, which causes the evaporator temperature to increase and the thermal performance of CLPHPs to decline (Ma, 2015) (Groll, 2003) (Liu, Fumin Shang, \& Dengying Li, 2012).

Khandekar and co-workers performed an experimental study on two CLPHPs having 20 turns of copper tubes with inner diameters of 2.0 and $1.0 \mathrm{~mm}$, respectively. The working fluids were water, ethanol, and R-123 with filling ratios of $30 \%, 50 \%$, and $70 \%$. The effect of the inclination angle was also investigated. The results showed that a combination of a large number of turns and a high input heat flux confirms continuous CLPHP operation in any inclination angle. Furthermore, they found that the CLPHPs with $50 \%$ filling ratio showed a better thermal performance and a higher performance limit, while the CLPHPs with $30 \%$ and $70 \%$ filling ratios experienced a dry-out of the evaporator and reached the critical state at lower thermal performances (Khandekar, N. Dollinger, \& M. Groll, Understanding operational regimes of closed loop pulsating heat pipes: An experimental Study, 2003).

Xiangdong Liu et al. performed experiment on CLPHP for analyzing the start-up performance with Water, Ethanol and Methanol as working fluids, they conclude as under the same working condition the start-up of CLPHP with methanol possesses the superiority of lowest start-up temperature and shortest start-up time while the CLPHP with water has the highest start-up temperature and required longest start-up time since Methanol has low dynamic viscosity, High value of saturation pressure gradient $\left(\frac{d P}{d T}_{s a t}\right)$, lower saturation temperature which helps it to perform better than other two fluids (Xiangdong Liu, 2013).
Piyanun Charoensawan et al. did experiment on CLPHPs with three different working fluids as Water, Ethanol, and R123. Experimental results indicates that thermo-physical properties of fluids with geometry of the device has effect on performance of CLPHP, $2 \mathrm{~mm}$ ID CLPHP with water as working fluid perform better than Ethanol and R123 filled CLPHP in vertical orientation but for $1 \mathrm{~mm}$ ID tube R123 and Ethanol perform better than Water as working fluid (Charoensawan, Sameer Khandekar, Manfred Groll, \& Pradit Terdtoon, 2003).

Therefore, in this study, first a CLPHP was designed and manufactured. Then, the effect of the most important parameters, including the working fluid (Methanol, Ethanol and DI Water), volumetric filling ratio $(40 \%, 50 \%, 60 \%$ and $70 \%)$, orientations and input heat power, on the thermal performance of the CLPHP were investigated experimentally.

\section{Description of experimental setup}

Setup consists of three section: evaporator, condenser and adiabatic sections. Evaporator section consists of an enclosure, U PVC tube having $100 \mathrm{~mm}$ ID, $105 \mathrm{~mm}$ OD and $200 \mathrm{~mm}$ length. Evaporator section of the CLPHP is suspended inside this enclosure by a cover plate. Cover plate consists of a circular PVC sheet of $110 \mathrm{~mm}$ diameter. 28 notches are made over the periphery of this plate to fix 28 copper tubes of 14 turn PHP. This plate is sealed to the top of the evaporator enclosure. Water is filled in evaporator enclosure. A $100 \mathrm{~mm}$ length of cartridge hater is inserted into evaporator section. The condenser section also consists of an enclosure, U PVC tube having $100 \mathrm{~mm}$ ID, $105 \mathrm{~mm}$ OD and $200 \mathrm{~mm}$ length. The condenser section of the CLPHP is completely submerged inside the enclosure. The CLPHP is attached to the enclosure by another cover plate like evaporator section. The condenser enclosure has inlet and outlet ports for water as heat absorbing medium.

A schematic diagram of the device used during the experimental tests is shown in Figure 1 pulsating heat pipe configured as a CLPHP was built using a capillary copper tube with $3 \mathrm{~mm}$ OD, $1.78 \mathrm{~mm}$ ID, and approximately $11 \mathrm{~m}$ length to form 28 parallel channels with 14 turns. The two end of copper tube in the manufactured PHP are connected using a three Tconnector. The first T-connector provides a connection between the vacuum system and the CLPHP, second T connector provides a connection between syringe pump and CLPHP and third T connector provides a connection between vacuum gauge and CLPHP. The CLPHP consisted of three regions: a heating section (evaporator), adiabatic section, and cooling section (condenser) with a height of $100 \mathrm{~mm}, 100 \mathrm{~mm}$, and $150 \mathrm{~mm}$, respectively. During the tests, the evaporator section was always below the cooling section. The total internal volume of the CLPHP was $32 \mathrm{cc}$. Copper was used for the pipe material so that supreme conduction heat transfer could be obtained in the condenser and 
evaporator. Pipes in the adiabatic section were also entirely insulated so that any heat losses from this part would also be minimized and so that the adiabatic assumption would be nearer to reality.

12 Chromel-Alumel (K type) thermocouples were applied to measure the system's temperature during the tests. Four thermocouples were placed in four turn of the evaporator section to measure the average evaporator temperature, two thermocouples were placed in the adiabatic zone, four thermocouples were placed in four turn of the condenser section to measure the average condenser temperature, and two thermocouples measured the inlet and outlet flow temperatures of the cooling section.

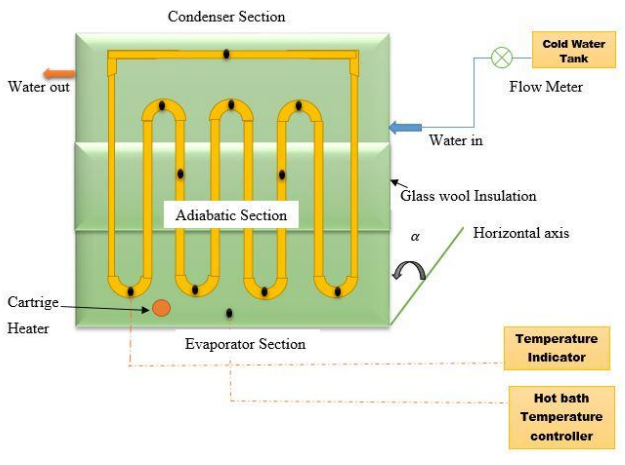

Fig. 1 Details of the Experimental set up

When filling the pipes with the working fluid, one must make sure of the fact that no incondensable gas leftovers in the working fluid and the system because the air inside the working fluid can adversely affect the hydrodynamic properties of the two phase flow, by evacuating the air from the system, the initial pressure of the system decreases and since the process of boiling and bubble formation speeds up, the performance of the system improves. Therefore, it is imperative that the amount of air in the system is kept to a least. In order to empty this air from the system and also to fill it with working fluid, a vacuum system was designed and fabricated. This system consists of the following: (a) a vacuum pump for emptying the gases inside the system, (b) chamber for storing the working fluid, and (c), hoses, and special valves for creating connections between the heat pipe, and the vacuum pump. This system has the capability to produce and maintain a vacuum of $0.1 \mathrm{~Pa}$.

\section{Procedures \& Results}

In the present experiment, three working fluids were employed, which were Methanol, Ethanol and DI Water. Tests were conducted for filling ratios of $40 \%$, $50 \%, 60 \%$ and $70 \%$ for three working fluids in vertical $\left(\theta=90^{\circ}\right)$, inclined $\left(\theta=45^{\circ}\right)$ and horizontal $\left(\theta=0^{\circ}\right)$ orientations with three Evaporator temperatures $40^{\circ} \mathrm{C}$ $50^{\circ} \mathrm{C}, 60^{\circ} \mathrm{C}$ and $70^{\circ} \mathrm{C}$. The CLPHP was partially filled by working fluid, then the evaporator temperature maintain constant at $50^{\circ} \mathrm{C}, 60{ }^{\circ} \mathrm{C}$ and $70{ }^{\circ} \mathrm{C}$, in condenser section constant mass flow rate is maintain by adjusting the outlet valve, as a result, the heat flux raises the temperature and pressure in the evaporator region. Therefore, the slugs and plugs moved within the pipe and transferred heat from the evaporator to the condenser. Thus, the system will reach a semisteady state after a certain period of time and the evaporator temperature will not change much. For different input heat powers, working fluids, and filling ratios and orientations, the average temperature differences between the evaporator and condenser were recorded.

The effect of filling ratio on the thermal resistance of CLPHP was studied. Fig. 2, Fig. 3 and Fig. 4 shows the effect of filling ratio on thermal resistance of CLPHP for three working fluids in vertical orientation. Thermal resistance of CLPHP is defined as $R=\frac{T_{e}-T_{c}}{Q} \quad$ Where $\mathrm{Te}$ and $\mathrm{T}_{\mathrm{c}}$ being the average wall temperature of the evaporator and condenser respectively and $Q$ is the input power.

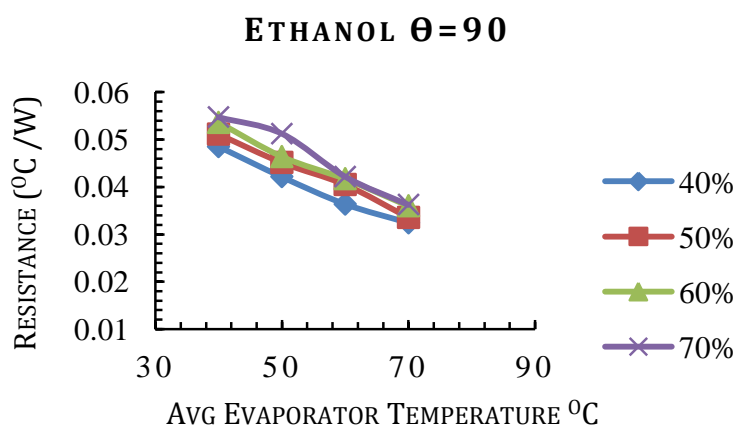

Fig. 2 Effect of filling ratio on thermal resistance for Ethanol in vertical orientation

METHANOL $\boldsymbol{\theta}=\mathbf{9 0}$

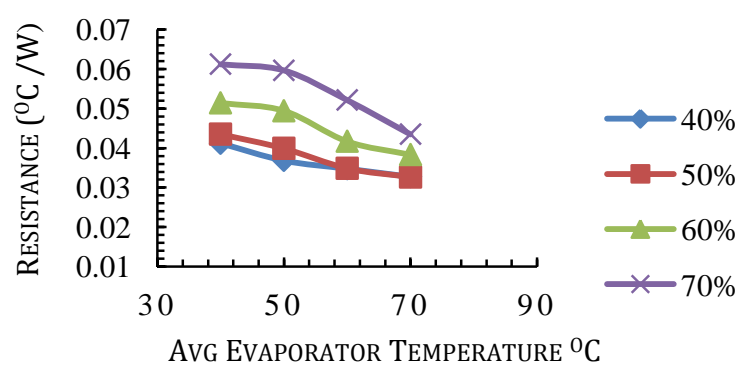

Fig. 3 Effect of filling ratio on thermal resistance for Methanol in vertical orientation

DI WATER $\boldsymbol{\theta}=\mathbf{9 0}$

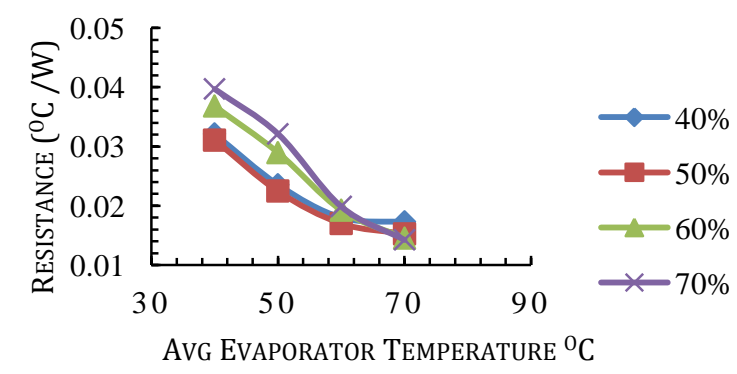

Fig. 4 Effect of filling ratio on thermal resistance for DI Water in vertical orientation. 
From Fig. 2, Fig. 3 and Fig. 4 it can be seen that as filling ratio increases, thermal resistance also increases, for higher filling ratios there are very less bubbles are present, the heat transfer occurs solely by convection. In CLPHP vapor bubbles are supposed to pulse and promote the liquid slug and dispel the heat from evaporator to the condensation section. In the PHP high fill ratio is responsible to hinder the pulsation of the bubble and hence the efficiency of heat transfer will not be very good. The low filling ratios are expected to favors the pulsation of the bubble, but it is extremely easy to dry out. Thus $40 \%, 50 \%$ and $50 \%$ were chosen as the optimum filling ratio for Ethanol, Methanol and DI Water.

\section{ETHANOL $50 \%$ FR}

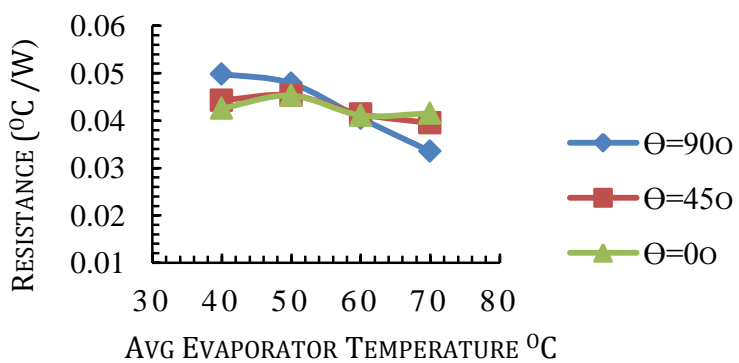

Fig. 5 Effect of orientation on thermal resistance for Ethanol at 50\% FR

METHANOL $50 \%$ FR

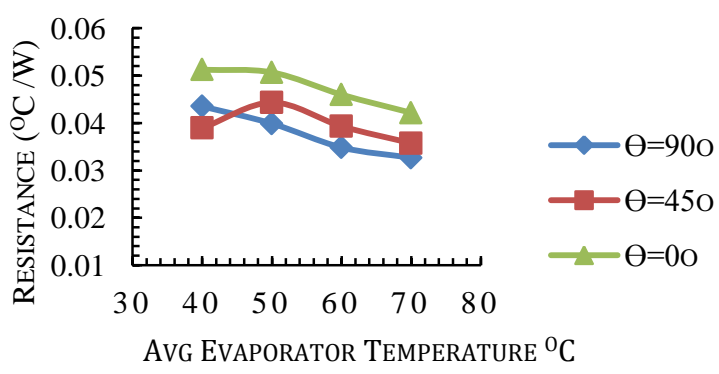

Fig. 6 Effect of orientation on thermal resistance for Methanol at 50\% FR

\section{WATER $50 \%$ FR}

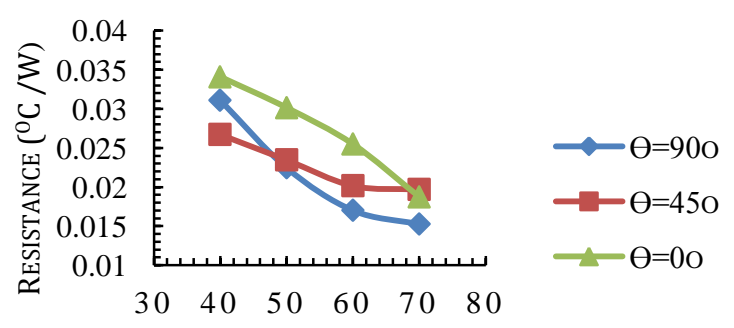

Avg EVAPORATOR TEMPERATURE ${ }^{\circ} \mathrm{C}$

Fig. 7 Effect of orientation on thermal resistance for DI Water at $50 \% \mathrm{FR}$

The performance of methanol is quite comparable to that of water. The thermodynamic properties of water make its performance better. Its high latent heat spreads more heat with less fluid flow. Experimentation were also conducted to study effect of working fluids on CLPHP at different orientations.

Fig. 5, Fig. 6 and Fig. 7 shows the effect of orientations on thermal resistance for Ethanol, Methanol and DI Water for 50\% filling ratios. In case of Ethanol at $60 \mathrm{oC}$ average evaporator temperature, resistance in all three orientations are $0.04045{ }^{\circ} \mathrm{C} / \mathrm{W}$, $0.04136{ }^{\circ} \mathrm{C} / \mathrm{W}$, and $0.04111{ }^{\circ} \mathrm{C} / \mathrm{W}$, which is almost constant. While when Methanol is used as working fluid with $50 \%$ filling ratio, resistance is minimum in $45^{\circ}$ orientation of CLPHP at $40^{\circ} \mathrm{C}$ Average evaporator temperature. In case of DI water with $50 \%$ filling ratio, resistance is higher at horizontal orientation and minimum at vertical orientation, while at $50{ }^{\circ} \mathrm{C}$ resistance is observed to be same in $45^{\circ}$ orientation and horizontal orientations.

In absence of gravity effect in horizontal orientation, Surface tension dominates. Which is responsible driving force behind the performance of CLPHP in horizontal orientation. The high surface tension of water creates additional friction and restricts the flow of liquid bubbles and vapor slugs formation, which directly reduce the pulsating action of working fluids inside the CLPHP. This problem can be overcome with the help of working fluids whose surface tension is lower than water like Methanol and Ethanol. From Fig. 5, it can be said that by the use of methanol at particular heat input, CLPHP acts as orientation free thermosyphon.

\section{Effect of Working Fluids on $\eta_{t h}$}

Fig. 8 to Fig. 11 shows the effect of working fluids on thermal efficiency at 40\% FR, 50\% FR, 60\% FR and $70 \%$ FR in vertical orientation with respect to variation in avg. evaporator temperature respectively.

Fig. 8 shows the Te Vs $\eta_{t h}$ for $40 \%$ FR at $\theta=90$ for Methanol, Ethanol and DI Water. From trends of the graph, it is observed that thermal efficiency of device is minimum, $23.38 \%$ at $70^{\circ} \mathrm{C}, 40 \%$ FR for Ethanol and maximum efficiency of device is $51.32 \%$ at $50{ }^{\circ} \mathrm{C}, 40 \%$ FR for Methanol.

Below results indicates that the in terms of thermal efficiency, Methanol and Ethanol filled CLPHP perform better than CLPHP charged with DI Water. The probable reason behind this performance is, Methanol and Ethanol has low dynamic viscosity, High value of saturation pressure gradient, lower saturation temperature which helps it to perform better than other fluid. The rate of growth of bubbles in evaporator section is inversely proportional to the latent heat, the fluids having very small latent heat enhances the growth of bubbles in evaporator section but this situation promotes the dry out condition at evaporator but this situation can be avoid by increasing the filling ratio. If high latent heat fluids used inside the CLPHPs than its reduces the pressure pulses and leads to minimize the oscillations inside the CLPHPs hence low latent heat fluids are preferable. 
$40 \%$ F R

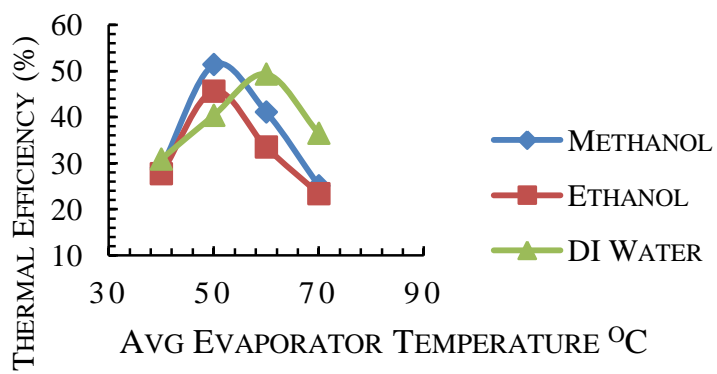

Fig. 8 Te Vs $\eta_{\text {th }}$ for $40 \%$ FR at $\theta=90$

Fig. 9 shows Te Vs $\eta_{t h}$ for $50 \%$ FR at $\Theta=90$ for Methanol, Ethanol and DI Water. From trends of the graph, it is observed that thermal efficiency of device is minimum, $23.95 \%$ at $70^{\circ} \mathrm{C}, 50 \% \mathrm{FR}$ for Methanol and maximum efficiency of device is $54.74 \%$ at $50^{\circ} \mathrm{C}, 50 \%$ FR for Ethanol.

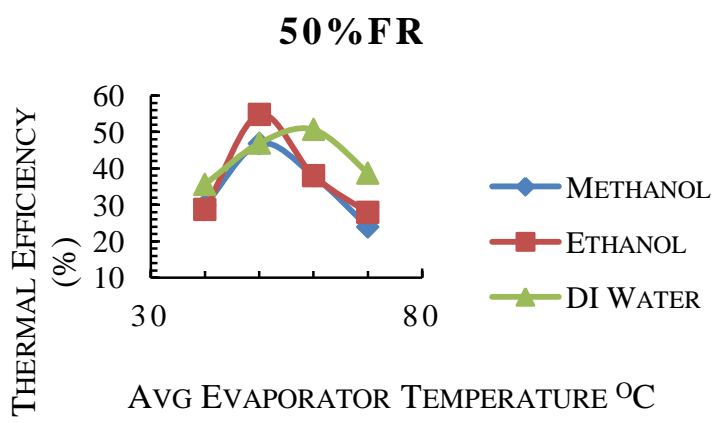

Fig. 9 Te Vs $\eta_{\text {th }}$ for $50 \%$ FR at $\Theta=90$

Fig. 10 shows the $\mathrm{T}_{\mathrm{e}}$ Vs $\eta_{t h}$ for $60 \% \mathrm{FR}$ at $\theta=90$ for Methanol, Ethanol and DI Water. From nature of the graph, it is observed that thermal efficiency of device is minimum, $18.24 \%$ at $70^{\circ} \mathrm{C}, 60 \% \mathrm{FR}$ for Methanol and maximum efficiency of device is $45.62 \%$ at $50^{\circ} \mathrm{C}, 60 \%$ FR for Ethanol.

\section{$60 \%$ F R}

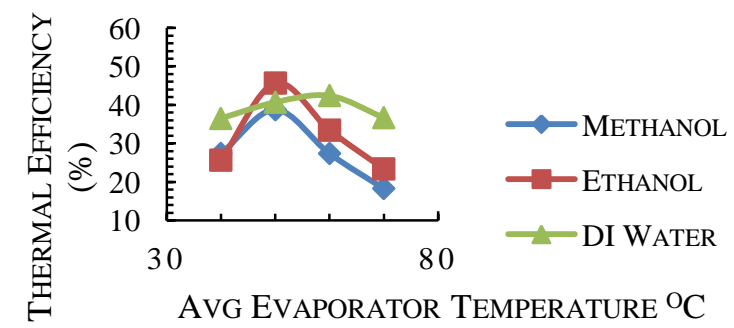

Fig. 10 Te Vs $\eta_{\text {th }}$ for $60 \%$ FR at $\theta=90$

Fig. 11 shows the Te Vs $\eta_{t h}$ for $70 \%$ FR at $\theta=90$ for Methanol, Ethanol and DI Water. From nature of the graph, it is observed that thermal efficiency of device is minimum, $16.34 \%$ at $40^{\circ} \mathrm{C}, 70 \% \mathrm{FR}$ for Ethanol and maximum efficiency of device is $39.81 \%$ at $60^{\circ} \mathrm{C}, 70 \%$
FR for DI Water.

\section{$70 \%$ F R}

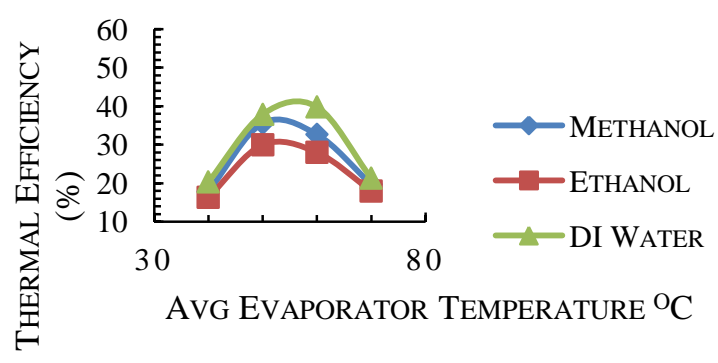

Fig. 11 Te Vs $\eta_{\text {th }}$ for $70 \%$ FR at $\theta=90$

High surface tension fluids are always preferable in wick heat pipes because of high capillary action is required in heat pipes. In pulsating heat pipes we required large amount of instability in form of liquids slugs and vapour plugs, if high surface tension fluid is used as working fluid than it retards the formation of unstable flow hence retardation in oscillations of PHPs, results into low thermal performance. PHPs need working fluids which are having low surface tension property. Methanol and ethanol having low surface tension since they gives better results in PHPs. High value of insures the small change in evaporator or condenser temperature gives the large change in pressure difference inside the working fluid hence maximum numbers of bubbles generation will occur which will aid thermal performance of CLPHPs.

\section{Effect of Filing Ratio on $\eta_{t h}$}

Fig. 12-Fig. 14 shows the effect of variation in filling ratios on thermal efficiency of CLPHP with respect to variation in avg. Evaporator temperature for Methanol, Ethanol and DI water in vertical orientation.

Fig. 12 shows the Te Vs $\eta_{t h}$ for Methanol at $\theta=90$, from nature of the graph it is observed the thermal efficiency of CLPHP is maximum, $51.32 \%$ at $40 \% \mathrm{FR}$, $50^{\circ} \mathrm{C}$ and minimum value is $17.88 \%$ at $70 \% \mathrm{FR}, 40^{\circ} \mathrm{C}$ for methanol in vertical orientation.

Fig. 14 shows the Te Vs $\eta_{t h}$ for DI water at $\theta=90$, from nature of the graph it is observed the thermal efficiency of CLPHP is maximum, $50.68 \%$ at $50 \% \mathrm{FR}$, $60^{\circ} \mathrm{C}$ and minimum value is $20.33 \%$ at $70 \% \mathrm{FR}, 40^{\circ} \mathrm{C}$ for DI Ware in vertical orientation.

From above observation, it is concluded that when the fill ratio is high enough, there are only few bubbles in tubes, and the effective oscillation can't be achieved. The flow friction between the fluid and the wall is increased as increasing of the fill ratio. The driving force for the oscillation and transportation of the heat from the evaporator to the condenser is decreased and thermal efficiency decreases at higher filling ratios. On the other hand, the volume of fluid is small, and the heat carried by the fluid is less, so the temperature difference between the evaporator and condenser is small, Thermal efficiency decreases. 


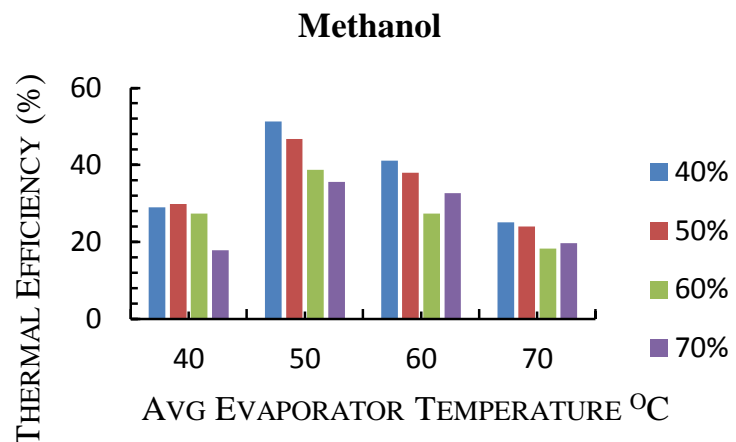

Fig. 12 Te Vs $\eta_{\text {th }}$ for Methanol at $\theta=90$

Ethanol

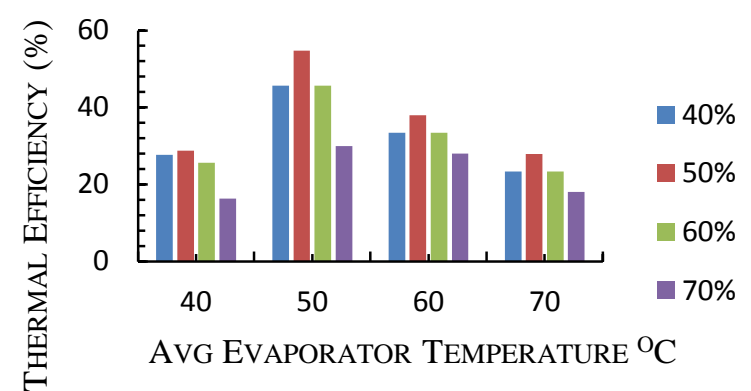

Fig. 13 Te Vs $\eta_{\text {th }}$ for Ethanol at $\theta=90$

Fig. 13 shows the Te Vs $\boldsymbol{\eta}_{\boldsymbol{t h}}$ for Ethanol at $\theta=90$, from nature of the graph it is observed the thermal efficiency of CLPHP is maximum, $54.74 \%$ at $50 \%$ FR, $50^{\circ} \mathrm{C}$ and minimum value is $16.35 \%$ at $70 \% \mathrm{FR}, 40^{\circ} \mathrm{C}$ for Ethanol in vertical orientation.

\section{Water}

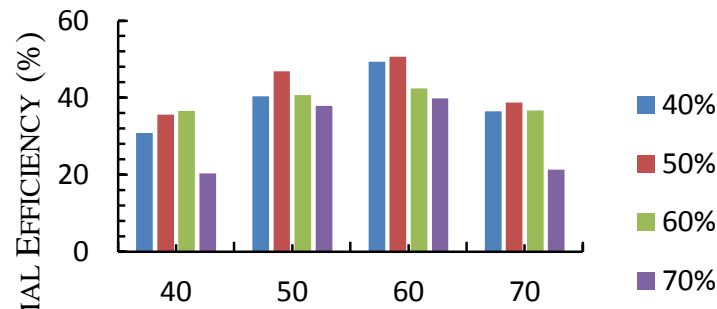

AVG EVAPORATOR TEMPERATURE ${ }^{\mathrm{O}} \mathrm{C}$

Fig. 14 Te Vs $\eta_{\text {th }}$ for DI Water at $\theta=90$

\section{Effect of Orientations on $\eta_{t h}$}

Fig. 15- Fig 17 shows Te Vs $\eta_{t h}$ at 50\% FR for Methanol, Ethanol and DI Water. Which indicates effects of variation in orientation on thermal efficiency of CLPHP.

Fig. 15 shows the effect of variation in orientation of CLPHP on $\eta_{t h}$ for Methanol at $50 \%$ FR. Maximum thermal efficiency of CLPHP is 46.76 which is observed at $\theta=90,50^{\circ} \mathrm{C} \mathrm{T}_{\mathrm{e}}$ and minimum value of thermal efficiency is $16.54 \%$ at $\theta=0,70{ }^{\circ} \mathrm{C} \mathrm{T}_{\mathrm{e}}$.

\section{Methanol 50\% FR}

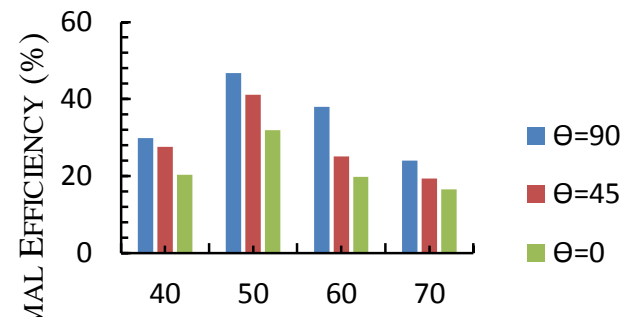

Avg Evaporator Temperature ${ }^{\circ} \mathrm{C}$

Fig. $15 \mathrm{Te}$ Vs $\eta_{\text {th }}$ for Methanol at $50 \% \mathrm{FR}$

Fig. 16 shows the effect of variation in orientation of CLPHP on $\boldsymbol{\eta}_{\text {th }}$ for Ethanol at 50\% FR. Maximum thermal efficiency of CLPHP is $54.76 \%$ which is observed at $\theta=90,50^{\circ} \mathrm{C} \mathrm{T}_{\mathrm{e}}$ and minimum value of thermal efficiency is $19.33 \%$ at $\theta=0,70{ }^{\circ} \mathrm{C} \mathrm{T}_{\mathrm{e}}$.

\section{Ethanol 50\% FR}

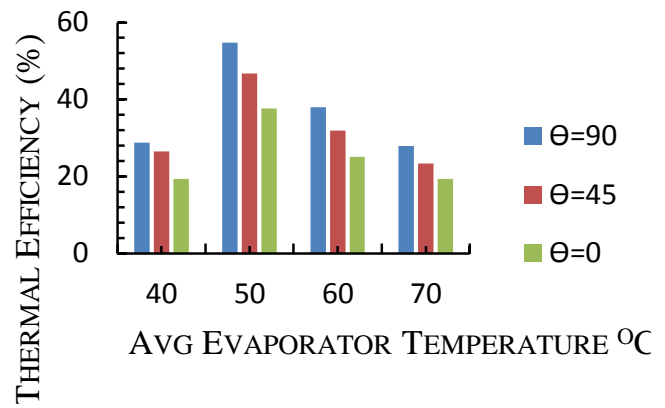

Fig. 16 Te Vs $\eta_{\text {th }}$ for Methanol at $50 \%$ FR

Fig 17 shows the effect of variation in orientation of CLPHP on $\eta_{t h}$ for DI Water at 50\% FR. Maximum thermal efficiency of CLPHP is $50.68 \%$ which is observed at $\theta=90,60^{\circ} \mathrm{C} \mathrm{T}_{\mathrm{e}}$ and minimum value of thermal efficiency is $23.51 \%$ at $\theta=0,40^{\circ} \mathrm{C} \mathrm{T}_{\mathrm{e}}$.

\section{Water 50\% FR}

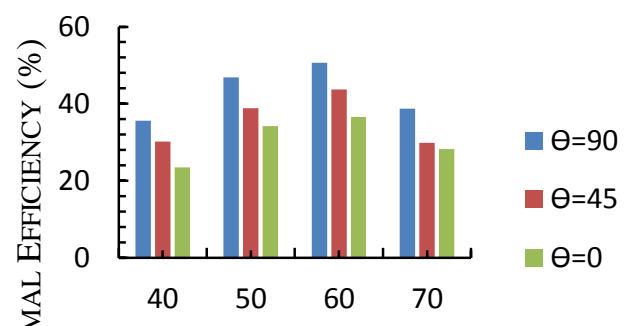

AVg EVAPORATOR TEMPERATURE ${ }^{\circ} \mathrm{C}$

Fig. $17 \mathrm{Te}$ Vs $\eta_{\text {th }}$ for Methanol at $50 \% \mathrm{FR}$ 
It may be because of increasing orientation, increases buoyancy force on up going vapour and gravity force on down coming liquid which gives rise to enhancement in performance with angle. In absence of gravity effect in horizontal orientation, Surface tension dominates. Which is responsible driving force behind the performance of CLPHP in horizontal orientation. The high surface tension of water creates additional friction and restricts the flow of liquid bubbles and vapor slugs formation, which directly reduce the pulsating action of working fluids inside the CLPHP.

\section{Conclusions}

The working range of close loop pulsating heat pipe is experimentally investigated to study the effects of various influencing parameters on performance. In this paper, attempted has been made to describe the effect of filling ratio and orientation of device on thermal resistance of CLPHP. The following conclusions can be drawn from the experimentation.

a) Different fluids are beneficial under different working conditions, an optimum tradeoff of various thermophysical properties has to be accomplished depending upon the enforced thermo-mechanical boundary conditions.

b) DI Water has Minimum thermal resistance because of the thermodynamic attributes of water makes it better than any other fluids for the pulsating heat pipes. Its high latent heat spreads more heat with less fluid flow. This result in low pressure drops and high power throughout. Its high thermal conductivity minimizes the temperature difference associated with conduction through the two phase flow in the PHP.

c) For Ethanol, variation in thermal resistance with respect to given heat input is very less as compare to other two fluids. Sometimes this types of properties are desirable in working fluids. This feature makes it acceptable and preferable where given heat input is not constant and fluctuation in nature.

d) The CLPHP is do not operate adequate at very high and very low filling ratio, There are two extreme possibilities of the fill volume that is $100 \%$ and $0 \%$. True operating range of device observed in between $30 \%$ and $70 \%$ fill volume.

e) The heat transfer rate increases with the fill ratio, and it reaches the maximum heat transfer rate at the fill ratio $40 \%$ to $50 \%$. The heat transfer performance decreases as fill ratio increases when the fill ratio is over $50 \%$. f) One of the aims of effective CLPHP design is to make thermal performance, as far as possible, independent of operating orientations. At a first glance, two physical phenomenon effects the thermal performance of CLPHP with respect to orientation, the first is gravity and second is numbers of meandering turns on the level of internal pressure distribution. This thesis work highlights only effect of gravity as effect of orientation on thermal performance of CLPHP.

g) For all three fluids maximum resistance observed in horizontal direction and minimum in vertical orientation. Heat transfer coefficient is higher in vertical orientation and lower in horizontal orientation. Thermal efficiency is maximum in vertical orientation and minimum in horizontal orientation.

\section{References}

Charoensawan, P., Sameer Khandekar, Manfred Groll, \& Pradit Terdtoon. (2003). Closed loop pulsating heat pipes Part A: parametric experimental investigations. Applied Thermal Engineering, 23, 2009-2020.

Groll, S. K. (2003). ON THE DEFINATION OF PULSATING HEAT PIPES: AN OVERVIEW. Proc. 5th Minsk International Seminar( Heat Pipes, Heat Pumps and Refrigerators) Belarus.

H. B. Ma, B. B. (2008). Heat Transport Capability in an Oscillating Heat Pipe. Journal of Heat Transfer, ASME., 130, 081501-7.

Kambiz Jahani, M. M. (2013). Promising Technology for Electronic Cooling: Nanofluidic Micro Pulsating Heat Pipes. Journal of Electronic Packaging, ASME., 135, 0210051-9.

Khandekar, S., M. Groll, P. Charoensawan, S. Rittidech, \& P. Terdto. (2004). CLOSED AND OPEN LOOP PULSATING HEAT PIPES. 13th International Heat Pipe Conference. Shanghai,Chaina.

Khandekar, S., N. Dollinger, \& M. Groll. (2003). Understanding operational regimes of closed loop pulsating heat pipes: An experimental Study. Applied Thermal Engineering, 23, 707-719.

Liu, J., Fumin Shang, \& Dengying Li. (2012). Experimental Study on Enhanced Heat Transfer Characteristis of Synergistic Coupling between the Pulsating Heat Pipes. 2012 International Conference on Future Energy, Environment, and Materials.Elsevier.

Ma, H. (2015). Oscillating Heat Pipes. New York Heidelberg Dordrecht London: Springer.

Reay, D., \& P.A. Kew. (2006). Heat Pipes. Burlington, MA 01803, USA: Elsevier.

Xiangdong Liu, Y. C. (2013). Dynamic performance analysis on start-up of closed-loop pulsating heat pipes (CLPHPs). International Journal of Thermal Sciences , 65 , 224-233.

Zohuri, B. (2011). Heat Pipes Design and Technology. Boca Raton, FL 33487-2742: Taylor \& Francis Group. 